\title{
Makna Simbolik Pratima Hyang Ratu di Pura Dadia Se-Desa Adat Krobokan Kabupaten Badung
}

\author{
Ni Nyoman Sri Widiasih ${ }^{1}$, I Gede Rudia Adiputra ${ }^{2}$, I Nyoman Kiriana ${ }^{3}$ \\ ${ }^{123}$ Universitas Hindu Negeri I Gusti Bagus Sugriwa Denpasar \\ ${ }^{1}$ newmanwid@gmail.com, ${ }^{2}$ gedeadiputra@gmail.com, ${ }^{3}$ kiriana@uhnsugriwa.ac.id.
}

\begin{abstract}
The existence of Hindus in the world cannot be separated from the use of media or symbols to worship God, one of which is pratima (in Balinese it is called pretima). Pratima Hyang and Ratu, when viewed from the history of the development of the art of sculpture, the paired statues (husband and wife) can be suspected as the embodiment of the spirits of the kings as rulers of the region, while Pratima Hyang can be suspected as the oracle of Hyang Widhi'sbecause the prestigepralingga used is in the form of an ox that can be used as an ox. identified with the prebhawa Hyang Widhi, namely Dewa Iswara riding a white ox. This research using descriptive qualitative methods. The approach used in this research is the approach Exfost facto. The theory used in this research is a symbol theory. This type of data and research are primary data and secondary data. The symbolic meanings of pratima Hyang and Ratu include: a) the meaning of holiness, meaning that by worshiping and honoring pratima Hyang and Ratu in the temple, it is expected to awaken and maintain the sanctity of the hearts of the worshipers; $b$ ) the meaning of the leadership of pratima Ratu with the title Ratu means to lead, it is hoped that the worshipers of pratima and the temple concerned are able to lead their deities in an effort to strengthen and increase srada bhakti to the gods and ancestors; c) the meaning of harmony and unity means that through the existence of pratima Hyang and Ratu, it can grow, awaken, and strengthen the spirit of harmony of the people who carry the pratima and the temple concerned.
\end{abstract}

Keywords: Symbolic Meaning; Pratima Hyang Ratu

\section{Abstrak}

Keberadaan umat Hindu di dunia tidak lepas dari penggunaan media atau simbol untuk berbhakti kepada Tuhan, salah satu diantara media itu adalah pratima (dalam bahasa Bali disebut pretima). Pratima Hyang dan Ratu, jika ditinjau dari sejarah perkembangan seni arca maka arca berpasangan (suami istri) dapat diduga sebagai perwujudan arwah raja-raja sebagai penguasa wilayah, sedangkan pratima Hyang dapat diduga sebagai atau stana prabawa Hyang Widhi karena pralingga yang digunakan berupa lembu yang dapat diidentikkan dengan wahana prebhawa Hyang Widhi yakni Dewa Iswara menunggangi lembu putih. Penelitian ini menggunakan metode kualitatif deskriptif. Pendekatan yang digunakan dalam penelitian ini adalah pendekatan Exfost facto. Teori yang digunakan dalam penelitian ini adalah teori simbol. Jenis data dan penelitian ini adalah data primer dan data sekunder. Adapun makna simbolik pratima Hyang dan Ratu meliputi: a) makna kesucian, maksudnya dengan memuja dan menstanakan pratima Hyang dan Ratu di pura diharapkan dapat membangkitkan dan merawat kesucian hati umat penyungsungnya; b) makna kepemimpinan pratima Ratu dengan gelar Ratu bermakna memimpin, maka diharapkan kepada umat pengemong pratima dan pura bersangkutan mampu memimpin warganya dalam upaya memperkokoh dan meningkatkan srada bhakti kepada istadewata dan leluhur; c) makna kerukunan dan persatuan maksudnya melalui keberadaan pratima Hyang dan Ratu dapat menumbuhkan, membangkitkan, dan memperkokoh semangat kerukunan umat penyungsung pratima dan pura bersangkutan.

Kata Kunci: Makna Simbolik; Pratima Hyang Guru 


\section{Pendahuluan}

Kehidupan yang rukun harmonis, aman, damai dinamis dan sejahtera merupakan dambaan setiap orang di dunia ini. Membangun kehidupan bersama yang harmonis, dinamis dan produktif membutuhkan landasan filosofis yang benar, tepat dan adaptif. Dengan demikian kehidupan bersama dalam suatu komunitas baik itu banjar, desa adat maupun penyungsungan pura akan menjadi wadah bagi setiap insan yang mendambakan kesejahteraan lahir batin secara utuh dan berkesinambungan. Dalam kaitan itu agama Hindu telah mengajarkan landasan hidup yang disebut konsep Tri Hita Karana, yaitu tiga penyebab terwujudnya kebahagiaan meliputi : (1) palemahan yang bermakna hubungan harmonis antara manusia dengan lingkungan; (2) hubungan antara manusia dengan manusia disebut Pawongan; dan (3) hubungan antara manusia dengan Tuhan disebut Parahyangan (Wirawan, 2011).

Hubungan yang harmonis antara manusia dengan sesama manusia diwujudkan dalam kehidupan yang tertib dan saling menghargai dalam bermasyarakat berbangsa dan bernegara. Hubungan yang harmonis dengan lingkungan diwujudkan dengan menjaga kelestarian alam sekitar. Umat Hindu menyadari bahwa manusia dan alam sama-sama ciptaan Tuhan, dan manusia sangat membutuhkan adanya alam yang sehat dan lestari sehingga oleh karena itu perlu diciptakan hubungan yang harmonis antara manusia dengan alam lingkungan. Hubungan yang harmonis dengan Tuhan diwujudkan dengan cara berbakti kepada Tuhan melalui jalan mempelajari ajaran agama, mendirikan dan merawat tempat suci atau pura, melaksanakan/ mengamalkan ajaran agama dengan benar, seimbang dan seutuhnya sesuai kemampuan, serta sesuai kompetensi dan profesi masing-masing.

Masyarakat Bali yang kehidupan beragamanya dewasa ini telah memasuki era perpaduan antara tradisi dan modernisasi tetap menempatkan Weda dan Susastra agama seperti tuntunan dalam berbagai pustaka lontar sebagai sumber ajarannya. Perpaduan ini otomatis akan memberikan nuansa yang baru, serta memiliki sedikit perbedaan antar daerah serta antar desa. Desa-desa tradisional yang tersebar di Bali senantiasa memiliki banyak kearifan lokal atau local genius serta berakar pada warisan budaya leluhurnya (Peterson, 2017). Pura sebagai tempat pemujaan terhadap Ida Sang Hyang Widi Wasa adalah salah satu tempat untuk menumbuhkan dan merawat Sraddha serta rasa bhakti serta mengadakan hubungan dengan Tuhan Yang Maha Esa (Ida Sang Hyang Widhi) yang berwujud niskala. Keberadan Tuhan yang berwujud niskala itu perlu diwujudkan dalam alam pikiran manusia karena tanpa perwujudan itu pikiran manusia sangat sulit terarah dan kurang mantap untuk melakukan pemujaan terhadap-Nya, kendati dalam mewujudkan itu sulit dilakukan (Samiyono, 2013). Oleh karena itu untuk memantapkan dan melaksanakan keyakinan umat Hindu terhadap-Nya maka umat Hindu mendirikan tempat pemujaan kepada Tuhan Yang Maha Esa, baik berupa sanggah, pura atau kuil yang dilengkapi dengan arca ataupun patung pemujaan sebagai media berbhakti kepada Tuhan dan arwah suci leluhur. Penggunaan arca sebagai media pemujaan telah terjadi sejak ribuan tahun mulai dari India sampai ke Indonesia termasuk di Bali dan eksis sampai sekarang.

Berkenaan dengan Pura sebagai sarana untuk mendekatkan diri kepada Sang Hyang Widhi Wasa (Tuhan Yang Maha Esa), maka Pura dapat dikelompokan menjadi empat macam yaitu : (1) Pura untuk memuja dan mengagungkan kebesaran Sang Hyang Widhi Wasa/Tuhan Yang Maha Esa dengan berbagai manifestasi-Nya disebut Pura Kahyangan (Sad Khayangan) atau Kahyangan Jagat. (2) Pura tempat suci yang didirikan untuk mengenang jasa para pemimpin kerohanian (Dang Hyang) disebut Dang Kahyangan, (3) Pura yang digolongkan fungsionaris seperti Pura Segara di Pantai penyungsungan para nelayan, Pura di Sawah disebut Pura Subak, Pura di Pasar disebut Pura Melanting. (4) Pura atau tempat suci untuk memuja Roh Suci Leluhur yang sudah dipandang suci atau Roh Para Rsi yang telah dianggap menjadi Dewa-Dewa atau Batara-Batari ini disebut Pura Dadia, Pura Paibon, Pura Kawitan atau Pura Pedharman (Punyaatmadja, 1993). 
Berkenaan dengan pura sebagai sarana untuk mendekatkan diri kepada Sang Hyang Widhi / Tuhan Yang Maha Esa, maka sesuai dengan pengelompokan pura menurut (Parisada, 2001) dapat dikelompokan menjadi empat macam yaitu : (1) Pura untuk memuja dan menggunakan kebesaran Sang Hyang Widhi Wasa / Tuhan Yang Maha Esa dengan berbagai manifestasi-Nya disebut Pura Kahyangan (Sad Khayangan). (2) Pura tempat suci yang didirikan untuk mengenang jasa para pemimpin kerohanian (Dang Hyang) disebut Dang Kahyangan. (3) Pura yang digolongkan fungsionaris seperti Pura Segara di Pantai, Pura di Sawah, Pura di Pasar. (4) Pura atau tempat suci untuk memuja Roh Suci Leluhur / yang sudah dipandang suci atau Roh para Rsi yang dianggap telah menjadi Dewa-Dewa atau BhataraBhatari ini disebut Pura Dadya, Pura Kawitan, atau pura Pedharman (Suasmini, 2017).

Demikianlah berbagai aktifitas keagamaan yang menyangkut keberadaan pura tersebut telah dilaksanakan oleh para penyungsung secara tradisi tanpa mengetahui secara jelas makna serta nilai yang terkandung di dalamnya termasuk kurang dipahami mengenai bentuk, fungsi dan makna pratima yang disungsung di masing-masing Pura Dadia. Dalam penelitian ini akan dikaji tentang Bentuk, Fungsi dan Makna Pratima Hyang dan Ratu di Pura Dadia se-Desa Adat Kerobokan. Berdasarkan fenomena-fenomena tersebut di atas penulis tertarik untuk mengkaji eksistensi pratima yang berada di Pura Dadia di Desa Adat Kerobokan Kec. Kuta Utara Kabupaten Badung Bali dalam sebuah penelitian.

\section{Metode}

Artikel ini merupakan hasil panelitian kualitatif deskriptif. Dengan menggunakan pendekatan Exfost facto yaitu suatu pendekatan yang digunakan untuk mengkaji suatu permasalahan yang telah terjadi untuk diteliti pada masa sekarang untuk mendapatkan data yang akurat dan jelas sesuai dengan keadaan yang sebenarnya (Sugiyono, 2018). Sebagai subjek dalam penelitian ini adalah warga di Desa Adat Kerobokan Kabupaten Badung Bali. Dalam penelitian ini yang menjadi objek penelitian adalah Pura Dadia khususnya Pratima Hyang-Ratu di Desa Adat Kerobokan Kabupaten Badung. Pemilihan objek ini berdasarkan atas gejala yang telah terjadi sekian lama akan tetapi segi nilai yang membuat masyarakat tetap memakai dan nyungsung Pratima Hyang Ratu di Pura Dadia, namun masih kabur dalam pemaknaan sehingga menarik untuk dikaji. Sumber data dalam penelitian ini diperoleh dari data primer dan sekunder. Adapun teknik pengumpulan data yang digunakan dalam penelitian ini adalah teknik observasi atau pengamatan berperan serta, wawancara, studi pustaka serta pencatatan dokumen sebagai metode pelengkap (Iskandar, 2019). Teori yang digunakan dalam penelitian ini adalah teori simbol.

\section{Hasil dan Pembahasan}

\section{Sejarah Singkat Desa Adat Kerobokan}

Mengenai sejarah Desa Adat Kerobokan dapat dijumpai dalam Eka Ilikita Desa Adat Kerobokan yang secara garis besarnya dinyatakan bahwa pada tahun saka 1702, ( tahun 1780 M) Kyayi Agung Ngurah Pemecutan yang menjadi raja di Pemecutan yang bergelar Sri Maha Sakti Pemecutan. Pada saat itu beliau ingin melaksanakan yajnya yang sarananya antara lain binatang-binatang yang terdapat di hutan yang akan dipergunakan untuk yajnya seperti : singa, macan, kidang dan lain-lain. Beliau sadar memiliki rakyat dari Pegatepan Gelgel Klungkung yang bernama I Gusti Bendesa Selat. Beliau diperintah oleh Ida Maharaja Sakti Pemecutan untuk mencari binatang hutan yang akan dipergunakan untuk uapacara yadnya tersebut. Atas titah raja maka I Gusti Bendesa Selat pergi ke Alas Jembrana yang diikuti oleh 20 orang anggota. Setelah 10 hari pergi dari Puri Pemecutan untuk berburu akhirnya I Gusti Bendesa Selat datang membawa hasil buruan berupa banyak binatang yang akan dipakai upacara. Sri Maharaja Pemecutan sangat senang akan kepintaran berburu rakyatnya itu. 
Atas kenyataan itu I Gusti Bendesa Selat diberikan hadiah berupa tanah yang terletak di Desa Padang Lambih Kangin yang dikuasai oleh I Gusti Ngurah Batu Lepang yang merupakan keturunan dari Arya Kepakisan. Pada waktu itu I Gusti Ngurah Bendesa Selat menjadi Lurah di Padang Lambih Kauh. Pada waktu pemerintahan I Gusti Bendesa Selat daerah menjadi aman, dan tentram serta rakyat semuanya menjadi senang. I Gusti Bendesa Selat memiliki dua orang putra, yang sulung bernam IGusti Wayahan Bendesa Mas, sedangkan adiknya bernam I Gusti Nengah Bendesa Mas. Kedua anakanya tersebut sangat rukun dan hidup cukup makmur. Setelah tua I Gusti Bendesa Selat berkeinganan putranya sulungnya menjadi lurah di Padang Lambih Kauh, namun putranya yang kedua yaitu I Gusti Nengah Bendesa Mas tidak mau menyerahkan wilayahnya kepada kakaknya dan beliau ingin wilayah tersebut dibagi menjadi dua agar masing-masing putranya bisa memerintah.

Semenjak itu timbulah perselisihan diantara kedua putra I Gusti Bendesa Selat itu. Setelah I Gusti Bendesa Selat meninggal dunia perselisahan diantara kedua putranya semakin meruncing karena kedua putranya tetap pada pendirian mereka masing-masing. Akibat terjadi perselisihan diantara mereka berdua menyebabkan rakyat dan prajurit pecah menjadi dua. Sebagian diperintah ole I Gusti Wayahan Bendesa Mas, sedangkan sebagian lagi diperintah oleh adiknya yakni I Gusti Nengah Bendesa Mas. Belakangan terjadilah perang sangat dasyat yang menyebabkan banyak prajurit gugur dan kehancuran Desa Padang Lambih Kauh. Prajurit bertempur saling tombak yang mengeluarkan darah sehingga darah menggalir sampai berbunyi krabak-krobok. Pada saat perang berlangsung I Gusti Wayahan Bendesa Mas menghadap kepada Ida Sri Maharaja Pemecutan di Puri Agung Pemecutan sekaligus menyampaikan situasi di Padang Lambih Kauh tidak aman. I Gusti Wayahan Bendesa Mas memohon kepada raja Ida Sri Maharaja Pemecutan agar putra beliau berkenan menetap di Padang Lambih Kauh. Kemudian raja Ida Sri Maharaja Pemecutan memberikan putra beliau yang bernama Kiayi Ketut Kerobokan untuk menetap di Padang Lambih Kauh.

I Gusti Nengah Bendesa Mas menjadi marah mendengar permohonan kakaknya kepada Raja Pemecutan, selanjutnya I Gusti Nengah Bendesa Mas datang ke Puri Agung Pemecutan dan mencoba untuk meminta putra raja. Namun Ida Sri Maharaja Pemecutan menyampaikan bahwa putra raja sedang tidak ada di puri, sebab putra raja masih menuntut ilmu di Puri Agung Klungkung. Pada waktu itu I Gusti Nengah Bendesa Mas berniat mengambil putra raja yang bernama Kyiayi Lanang Wayahan Celuk tersebut dari Puri Agung Klungkung kemudian membawanya ke Badung agar anak tersebut tinggal di Desa Padang Lambih Kauh bagian Selatan. Sesudah kedua putra raja Pemecutan tersebut berada di Padang Lambih Kauh wilayah kembali menjadi aman. Putra Agung Pemecutan yang pertama berada di Jero Kajanan Kerobokan sedangkan adiknya Kyiayi Lanang Wayahan Celuk tinggal di Jero Kelodan Kerobokan. Sejak itu Desa Padang Lambih dirubah namanya menjadi Desa Kerobokan.

\section{Pratima Hyang Guru}

Keberadaan umat Hindu di dunia tidak lepas dari penggunaan media atau simbol untuk berbhakti kepada Tuhan, salah satu diantara media itu adalah pratima (dalam bahasa Bali disebut pretima). Pratima ( $m \bar{a}$ dengan $\bar{a}$ panjang bahasa Sanskerta) berarti: patung, gambaran, lukisan, bayangan, persamaan (Kanjeng, 1994).

Dalam Sri Reshi Anandakusuma (disebutkan bahwa pratima (pratima) diartikan arca yang disucikan (disakralkan) (Wiana, 2009). Krama Desa Adat Kerobokan khususnya pengemong Pura Dadia sudah terbiasa menyebutkan bahwa pratima adalah perwujudan dewa (Ista Dewata) sekaligus prebhawa Hyang Widhi dan juga prebhawa (bayangan manifestasi Bhatara Leluhur). Dalam kaitan upacara pujawali dan melasti semua pratima sebagai stana para ista dewata yang distanakan di pura bersangkutan. Ketika upacara melasti yang dilaksanakan di pantai Petitenget, hampir semua pratima pura Dadia se Desa Adat Kerobokan ikut Bersama melasti dengan diusung oleh masing-masing penyungsung pura Dadia 
bersangkutan dan berangkat bersamaan mengambil start di jaba pura Desa, Desa Adat Kerobokan. Sehari sebelum melasti dan setelah datang dari melasti, biasanya pratima distanakan di Bale Agung Pura Desa dan kembali ke Pura Dadia masing-masing pada hari pengerupukan. Pratima itu adalah bayangan ista dewata yang dipuja oleh krama Desa Adat Kerobokan, walaupun bayangan (pratima) tersebut tidak menyerupai dewa yang distanakan di pura bersangkutan.

\section{Makna Simbolik Pratima Hyang Guru di Pura Dadia Se-Desa Adat Krookan Kecamatan Kuta Utara, Kabupaten Badung \\ a. Makna Kesucian}

Memperhatikan perwujudan pratima Hyang dan Ratu khususnya arca pratima Hyang yang berwujud pandita (orang suci) dan juga sebutan Hyang yang bermakna suci, maka dapat ditegaskan bahwa arca tersebut bermakna kesucian. Maksudnya kekuatan yang dipuja ataupun yang distanakan di arca tersebut adalah kekuatan suci, baik suci karena proses penyucian maupun Beliau yang merupakan sumber dari kesucian yaitu Sang Hyang Widhi (Palguna, 2015). Berkaitan dengan makna kesucian tersebut yang juga bermakna Sang Hyang Widhi ada pandangan krama penyungsung sebagai berikut:

1) Pandangan pertama, pandita (orang suci) yang merupakan simbul dari Maha Purusa atau Parama Siwa yang bebas dari pengaruh maya (sakti dan guna) sehingga Beliau masih dalam kondisi suci murni. Demikian pula pandita (Rsi Agastya) adalah orang suci sekaligus tokoh agama yang diyakini berperan penting dan central dalam menyebarkan dan menegakkan Dharma (Agama) di Nusantara termasuk Bali, yang mana Beliau adalah penganut paham Siwa yang sangat memuliakan Siwa sebagai perwujudanTuhan.

2) Pandangan kedua menyatakan bahwa pratima Hyang merupakan perwujudan dari arwah suci leluhur yang telah bebas dari pengaruh dunia dan panca maya kosa, namun belum menjadi satu zat dengan Sang Hyang Widhi. Posisi seperti itu dalam lontar Wrespati Tatwa dinyatakan bahwa roh suci (BhataraLeluhur) sedang berada di alam salokya.

3) Pandangan yang ketiga menyatakan bahwa perwujudan pratima Hyang itu juga sebagai simbul kesucian. Ibarat Bhagawanta yang mendampingi Raja atau pemerintahan, sehingga kebijakan politik pemerintahan Sang Ratu senantiasa memdapatkan pribasi kesucian dari orang suci (Pandita).

Berdasarkan uraian diatas maka sudah sepatutnya pura dengan seluruh areanya disebut sebagai tempat suci, karena yang distanakan disana adalah prabawa Hyang Widhi sebagai sumber kesucian, arwah suci leluhur yang telah mendewata di alam salokya, demikian pula pribadi kesucian Bhagawanta niskala yang memberikan aura kesucian kepada para Pemangku (Pinandita), para pemimpin pengemong pura, maupun pemimpin (kepala keluarga di masingmasing keluarga penyungsung pura). Oleh karena itulah setiap umat Hindu jika akan memasuki areal pura baik kanista mandala (jaba sisi), maya mandala (jaba tengah), lebih-lebih utama mandala (jeroan) haruslah berpikiran dan berorientasi pada kesucian sakala (wahya) maupun niskala (adiatmika). Berkenaan dengan itu, agar supaya kesucian pura termasuk aura kesucian pratima tetap terjaga dan lestari maka aktivitas di pura senantiasa dirangkaikan dengan upacara mesuci-suci, minimal penyucian dilakukan melalui tirta pembersihan maupun tirta penglukatan.

Terkait dengan kesucian (makna kesucian) maka umat Hindu dimanapun berada wajib berperilaku yang mendukung suasana kesucian. Hal itu dapat dilakukan melalui pengamalan tri kaya parisuda, melaksanakan prosesi pengelukatan termasuk praktik pengendalian. 


\section{b. Makna Kepemimpinan}

Pratima Ratu berwujud Purusa (laki-laki) dan Prakerti (wanita) yang memiliki arti simbolis Purusa dan Prakerti telah menyatu yang akan menghasilkan alam semesta beserta seluruh isinya termasuk terciptanya bermiliar-miliar manusia, binatang, dan tumbuhan. Berkaitan dengan penyungsungan pura dan pratima Ratu maka para penyungsung itu patut ada yang mengendalikan yang secara irarkhi semua penyungsung pura itu dikendalikan oleh kekuatan di atas dirinya secara berjenjang, dari yang paling dekat (nyata) yakni orang tua, selanjutnya oleh kakek nenek sampai leluhur yang telah mendewata. Demikianlah para bhakta penyungsung pura sekaligus penyungsung pratima Ratu senantiasa memohon tuntunan dan perlindungan kepada beliau yang distanakan di pelinggih pura maupun yang distanakan melalui media pratima Ratu. Perwujudan arca ratu juga dimaksudkan bahwa arwah leluhur yang telah mendewata dapat menguasai dan mengendalikan kekuatan Rwabineda agar dapat berjalan seimbang, searah dan seiring demi terwujudnya kehidupan yang tentram dan sejahtera di bhuwana agung maupun bhuwana alit (Mehta, 2017). Berdasarkan uraian itu tampak dengan jelas bahwa pratima Ratu dengan Purusa Prakerti (laki-laki perempuan) memiliki makna kepemimpinan yaitu kekuatan yang dipuja di pura selalu dimohonkan untuk menuntun masyarakat penyungsungnya.

Ratu dimaknai sebagai penguasa raja dengan permaisuri atau ayah dan ibu yang merupakan pemimpin terdekat yang selalu memberikan bimbingan, pengawasan dan perlindungan kepada generasi penerusnya. Umat yang bhakti pada Leluhur wajiblah siap untuk dipimpin dan siap melaksanakan tuntunan nya.

\section{c. Makna Kerukunan dan Persatuan}

Pura Dadia dengan pratimanya (Hyang-Ratu) sebagai perwujudan kekuatan yang dipuja oleh penyungsung pura berpengaruh sangat besar terhadap keyakinan umat penyungsungnya. Hal ini terjadi mengingat tingkat pemahaman, keyakinan maupun penghayatan umat Hindu terhadap kekuatan yang dipuja selalu dan pasti beragam dan berjenjang. Realitas itu adalah fakta yang tak terbantahkan yang ada pada umat Hindu sehingga pengamalan atau praktik beragama Hindu diajarkan melalui Catur Marga (Goris, 1984). Pada tingkatan bhakti dan karma umat Hindu sangat membutuhkan media, baik berupa bangunan pelinggih, pratima termasuk arca maupun sarana upakara yadnya lainnya. Umat Hindu krama Desa Adat Kerobokan lebih dari 90\% dominan pada tataran bhakti dan karma, sehingga masih sangat membutuhkan media berupa pratima maupun arca termasuk daksina sebagai pralingga. Akibat dari setiap pemujaan memerlukan media maka itulah umat penyungsug pura berusaha untuk hadir untuk memanjatkan puja baktinya kepada kekuatan yang dipuja yang diwujudkan dalam bentuk Pratima (Suarsini, 2018). Tanpa adanya pratima maka umat penyungsung pura merasakan; pertama sulit memusatkan pikiran untuk berbhakti, yang kedua umat terasa kurang mantap untuk melaksanakan puja bhakti persembahan pada hari-hari suci maupun hari raya lebih-lebih pada hari pujawali pada pura bersangkutan. Atas dasar itu maka kebijakan yang sering diambil dan sering dilaksanakan oleh para manggala krama dan penyungsung pura adalah dengan memberikan waktu yang cukup memadai kepada krama untuk sembahyang dengan cara bergantian sehingga umat dapat sembahyang dengan menyaksikan pratima pada pelinggih tempat pemujaan (bale pakelik/bale piyasan).

Dari kalangan anak-anak maupun umat dewasa keberadaan pratima sangat besar pengaruhnya terutama ketika dilaksanakan upacara melasti. Apabila tidak ada pratima yang diusung pada acara melasti, maka jelaslah umat penyungsung pura akan terpencar dan tidak terkoordinir. Demikian pula dengan ada pratima beserta jempananya menyebabkan umat penyungsung pura merasa dituntun dan dituntut untuk mampu rukun dan bersatu, karena tanpa bersatu maka jempana tidak ada yang mengusung, yang berarti pula bhakti kepada Leluhur tidak terjadi. Dari kondisi tersebut di atas, sangat mudah dipahami bahwa pratima memiliki 
makna kerukunan dan persatuan karena dapat merukunkan dan menyatukan umat penyungsungnya melalui kegiatan kebaktian dalam berbagai bentuknya yang dilaksanakan di pura maupun pada saat upacara melasti.

\section{Kesimpulan}

Sejarah Desa Adat Krobokan dimulai pada tahun saka 1702, (tahun 1780 M) Kyayi Agung Ngurah Pemecutan yang menjadi raja di Pemecutan yang bergelar Sri Maha Sakti Pemecutan Pratima Hyang Guru adalah bayangan ista dewata yang dipuja oleh krama Desa Adat Kerobokan, walaupun bayangan (pratima) tersebut tidak menyerupai dewa yang distanakan di pura bersangkutan. Pratima Hyang dan Ratu, jika ditinjau dari sejarah perkembangan seni arca maka arca berpasangan (suami istri) dapat diduga sebagai perwujudan arwah raja-raja sebagai penguasa wilayah, sedangkan pratima Hyang dapat diduga sebagai atau stana prabawa Hyang Widhi karena pralingga yang digunakan berupa lembu yang dapat diidentikkan dengan wahana prebhawa Hyang Widhi yakni Dewa Iswara menunggangi lembu putih. Adapun makna simbolik pratima Hyang dan Ratu meliputi: a) makna kesucian, maksudnya dengan memuja dan menstanakan pratima Hyang dan Ratu di pura diharapkan dapat membangkitkan dan merawat kesucian hati umat penyungsungnya; b) makna kepemimpinan pratima Ratu dengan gelar Ratu bermakna memimpin, maka diharapkan kepada umat pengemong pratima dan pura bersangkutan mampu memimpin warganya dalam upaya memperkokoh dan meningkatkan srada bhakti kepada istadewata dan leluhur; c) makna kerukunan dan persatuan makdusnya melalui keberadaan pratima Hyang dan Ratu dapat menumbuhkan, membangkitkan, dan memperkokoh semangat kerukunan dan persatuan umat penyungsung pratima dan pura bersangkutan.

\section{Daftar Pustaka}

Goris, R. (1984). The Religious Character of the Village Community, dalam Bali Studies in Life, Thought, and Ritual. Foris Publication.

Iskandar. (2019). Metodelogi Penelitian Kualitatif. Gaung Persada.

Kanjeng, I. N. (1994). Sarasamuccaya Dengan Teks Bahasa Sansekerta dan Jawa Kuna.

Mehta, R. (2017). Bertemu Tuhan Dalam Diri: Ulasan Sistem Pendidikan Dalam Kitab Upanisad. Yayasan Dharma Sastra.

Palguna, D. I. (2015). Shastra Wangsa (Kamus Istitah Wangsa Bali Pustaka, Pusaka Manusia). Sadampaty Aksara.

Peterson, J. V. (2017). Tri Hita Karana. In The International Encyclopedia of Primatology. https://doi.org/10.1002/9781119179313.wbprim0302

Punyaatmadja, I. O. (1993). Panca Sradha. Parisada Hindu Dharma Indonesia Pusat.

Samiyono, D. (2013). Resistensi Agama Dan Budaya Masyarakat. Walisongo: Jurnal Penelitian Sosial Keagamaan. https://doi.org/10.21580/ws.2013.21.2.244

Suarsini, N. N. (2018). Tradisi Ngelawang Pada Hari Raya Kuningan Di Desa Pakraman Asak Pugutan: Sebuah Kajian Etnolinguistik. Mabasindo, 2, 18.

Suasmini, I. D. A. S. (2017). Kebaya sebagai busana ke Pura Dalam Representasi Perempuan Kontemporer di Kota Denpasar. MUDRA Jurnal Seni Budaya, 32, 141-148.

Sugiyono. (2018). Metode Penelitian Kualitatif (Untuk penelitian yang bersifat: eksploratif, enterpretif, interaktif dan konstruktif. Alfabeta.

Wiana, I. K. (2009). Pura Besakih Hulunya Pulau Bali. Paramita Surabaya.

Wirawan, I. M. A. (2011). Tri Hita Karana: Kajian Teologi, Sosiologi dan Ekologi menurut Weda. Paramita. 